\title{
Designing Optically \& Utilization of Thermopile Chip with Resonant Cavity Absorber Structure as IR Absorber
}

\author{
Haigang Hou ${ }^{1}$, Jian Yang ${ }^{1}$, Guiwu Liu ${ }^{1}$, Junlin Liu ${ }^{1}$, Mudassar Abbas ${ }^{2}$, Shahid Hussain ${ }^{1, *} \oplus$, Haicheng Shao ${ }^{1}$, \\ Guanjun Qiao ${ }^{1, *}$, Ayman A. Ghfar ${ }^{3}\left(\mathbb{D}\right.$, Mohamed Ouladsmane ${ }^{3}$, Muhammad Tariq Nazir ${ }^{4, *}$ and \\ Murefah Mana AL-Anazy ${ }^{5}$
}

1 School of Materials Science and Engineering, Jiangsu University, Zhenjiang 212013, China; neil_kanth@yahoo.com (H.H.); xzzhang2018@ujs.edu.cn (J.Y.); gwliu76@ujs.edu.cn (G.L.); liujunlin@ujs.edu.cn (J.L.); shaohaicheng311@163.com (H.S.)

2 School of Textile and Design, University of Management and Technology, Lahore 54770, Pakistan; mudassar.abbas@umt.edu.pk

3 Advanced Materials Research Chair, Chemistry Department P. O. Box 2455, College of Science, King Saud University, Riyadh 11451, Saudi Arabia; Aghafr@ksu.edu.sa (A.A.G.); mouladsmane@ksu.edu.sa (M.O.)

4 School of Mechanical and Manufacturing Engineering, University of New South Wales, Sydney, NSW 2052, Australia

5 Department of Chemistry P. O. Box 84428, College of Science, Princess Nourah bint Abdulrahman University, Riyadh 11671, Saudi Arabia; mmalanazy@pnu.edu.sa

* Correspondence: shahid@ujs.edu.cn (S.H.); giqiao@ujs.edu.cn (G.Q.); tariq.nazir@unsw.edu.au (M.T.N.)

check for updates

Citation: Hou, H.; Yang, J.; Liu, G.; Liu, J.; Abbas, M.; Hussain, S.; Shao,

H.; Qiao, G.; Ghfar, A.A.;

Ouladsmane, M.; et al. Designing Optically \& Utilization of Thermopile Chip with Resonant Cavity Absorber Structure as IR Absorber. Coatings 2021, 11, 302. https://doi.org/ 10.3390/coatings11030302

Received: 5 February 2021

Accepted: 3 March 2021

Published: 6 March 2021

Publisher's Note: MDPI stays neutral with regard to jurisdictional claims in published maps and institutional affiliations.

Copyright: (c) 2021 by the authors. Licensee MDPI, Basel, Switzerland. This article is an open access article distributed under the terms and conditions of the Creative Commons Attribution (CC BY) license (https:/ / creativecommons.org/licenses/by/ $4.0 /)$.
Abstract: This paper presents a novel thermopile chip in which the resonant cavity structure was fully utilized as an absorber by an optical design. The resonant cavity absorber structure was designed using $\mathrm{Al}$ as anthe bottom reflective metal layer, air as the intermediate dielectric layer, and $\mathrm{SiO}_{2} / \mathrm{TiN} / \mathrm{Si}_{3} \mathrm{~N}_{4}$ sandwich layers as the top absorption layer, while the bottom reflective metal (Al) was deposited on the cold junctions of the thermopile. The simulation and calculation results show that the thermopile chip with resonant cavity absorber structure not only has great infrared absorption in the wide infrared absorption range but also can effectively prevent the cold junctions from absorbing infrared radiation and inhibit the rise of temperature. As a result, the temperature difference between the hot junctions and the cold junctions is increased, and the responsivity of the thermopile chip is further improved. Moreover, the duty cycle of the thermopile chip is greatly improved due to the double-layer suspension structure. Compared with the traditional thermopile chip structure, the sizes of the thermopile chip with the resonant cavity absorber structure can be further reduced while maintaining responsivity and specific detectivity.

Keywords: infrared detector; resonant cavity; energy applications; absorptance

\section{Introduction}

The thermopile IR detector is applied in many fields, because it has the advantages of no need for cooling and chopping, broad spectral response, low cost and simple output circuit [1-4]. The thermopile chip is the core component of thermopile IR detector and has been greatly optimized and has opened the door to mass production, with the help of conventional complementary metal oxide semiconductor (CMOS) and micro electromechanical system (MEMS) technologies. The thermopile chip is generally a central suspended structure with a supporting layer, thermopile, absorber, and other layers deposited on a silicon substrate. The hot junctions and the cold junctions of the thermopile are respectively distributed on the edge and center of the silicon substrate hollowed out in the center, and the hot junctions are covered by the absorber, as shown in Figure 1. The thermopile infrared detector contains two energy conversion processes of light-heat and heat-electricity, and its performance also depends on the superposition of the two conversions efficiency. Thus, the 
absorber can play a crucial role on the thermopile chip. The absorber is required for great absorption at both 3-5 $\mu \mathrm{m}$ and $8-14 \mu \mathrm{m}$, while a thermopile chip is used as the sensing element of an infrared thermometer [5,6], nondispersive infrared (NDIR) gas detector $[7,8]$ or infrared imager [9-11]. The porous materials with dendritic and soft structure, like gold-black, can have great absorption at ultra-wide wavelength range and are typically used as the absorber of thermopile chip [12-17]. However, these porous materials are generally too fragile and not compatible with CMOS [18,19]. Owing to the interference of light, the resonant cavity absorber structures can also have great absorption at a specific band and are also often used as the absorber of thermopile chips. However, the resonant absorption structure is a stack of multilayer films, so its absorption characteristics largely depend on the matching relationship between the refractive index and thickness of the multilayer film, and often only absorb specific wavelength bands. In addition, the resonant cavity absorption structure is often sensitive to thickness errors, and the thickness of each layer of the film needs to be accurately controlled during the preparation process. In fact, an $\mathrm{Si}_{3} \mathrm{~N}_{4}$ layer or $\mathrm{SiO}_{2} / \mathrm{Si}_{3} \mathrm{~N}_{4} / \mathrm{SiO}_{2}$ sandwich structure is also usually used as the absorber of thermopile chips. However, the $\mathrm{Si}_{3} \mathrm{~N}_{4}$ layer or $\mathrm{SiO}_{2} / \mathrm{Si}_{3} \mathrm{~N}_{4} / \mathrm{SiO}_{2}$ sandwich structure has higher absorption only at $8.5-13.5 \mu \mathrm{m}$ and lower absorption at $2.5-8 \mu \mathrm{m}[20,21]$.

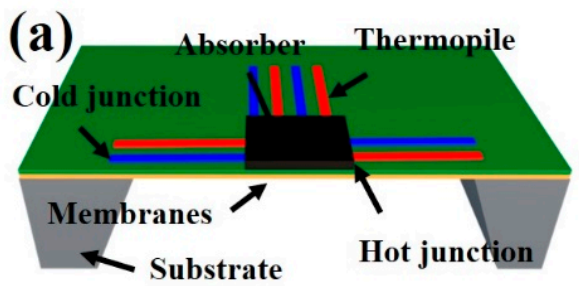

(c)

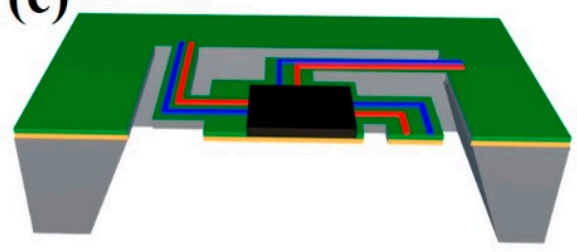

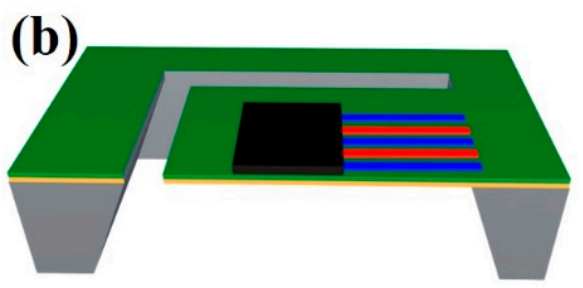

(d)

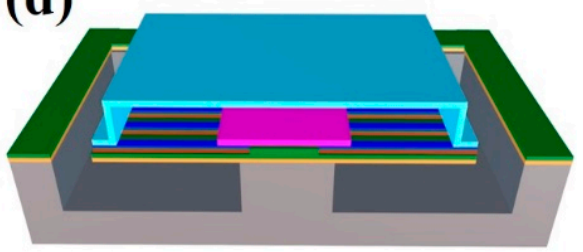

Figure 1. Typical thermopile chip structures: (a) close membrane structure, (b) cantilever beam structure (c) suspension bridge structure, and (d) the designed thermopile chip structure with resonant cavity.

The structures of thermopile chips are mainly divided into three types: close membrane structure, cantilever beam structure, and suspension bridge structure (Figure 1a-c) [22-25]. Compared to the cantilever beam and suspension bridge structures, the close membrane structure is the current mainstream structure of thermopile chip, which is provided with smaller thermal resistance, shorter response time, and a simpler manufacturing process. However, the above chip structures all have the problem of mutual restriction between the absorption zone and the thermocouple zone, and further reduction in thermopile chip size cannot maintain relatively higher responsivity and detectivity.

In this paper, we designed a novel thermopile chip in which the resonant cavity structure was fully utilized as an infrared absorber by an optical design (Figure 1d). In the resonant cavity absorber structure, the $\mathrm{Al}$, air, and $\mathrm{SiO}_{2} / \mathrm{TiN} / \mathrm{Si}_{3} \mathrm{~N}_{4}$ sandwich layers were used as the bottom reflective metal layer, intermediate dielectric layer and top absorption layer, respectively. The designed thermopile chip was proven to be provided with a high duty cycle, great infrared absorption, and a wide infrared absorption range.

\section{Design of Resonant Cavity Absorber Structure}

As shown in Figure 2a, the resonant cavity absorber structure generally consists of three parts: the top absorption metal layer, the middle dielectric layer, and the bottom 
reflective metal layer [26,27]. The absorption characteristics of the resonant cavity absorber structure are based on the theory of optical interference absorption. The incident light and reflected light will produce light interference effects at the top absorption metal layer when the optical thickness of middle dielectric layer is of a quarter-wavelength thickness, thereby achieving higher infrared absorption at specific band. Thus, it is difficult for the resonant cavity absorber structure to achieve ultra-wide spectral absorption like the porous materials and to realize a detector in various fields such as gas detection and non-contact human temperature measurement. Moreover, the matching of each thin film, especially the thickness, has a great influence on the absorption characteristics of the resonant cavity absorber structure. Thus, the resonant cavity absorber structure generally requires a precise design of the absorption structure and control of the manufacturing process.

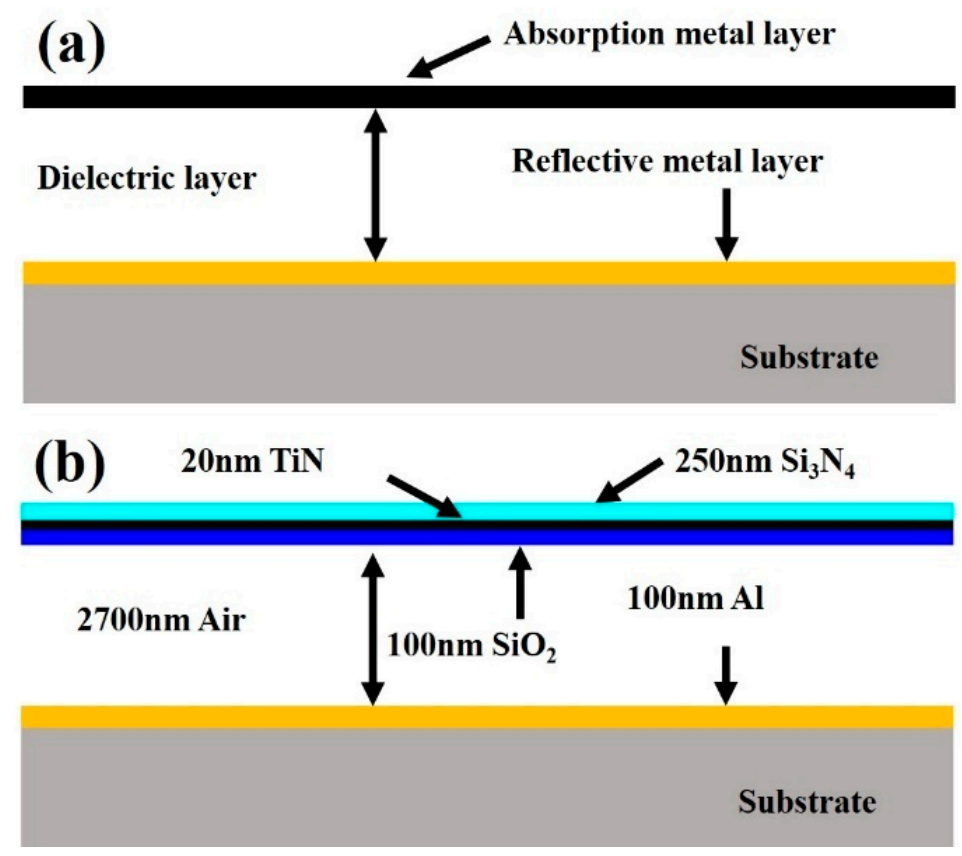

Figure 2. Schematics of (a) common and (b) the designed resonant cavity absorber structures.

The Essential Macleod is a simulation software for the transmission, reflection and absorption characteristics of optical multilayer films. In order to design a resonant cavity absorber structure with broad spectrum absorption and low film thickness error sensitivity, we first used the Essential Macleod to simulate and calculate the reflection and absorption characteristics of different materials based on the theory of optical interference absorption and then chose reasonable materials for each layer of the resonant cavity absorber structure, as shown in Figure 3. The simulation results show that the average reflectance of the Al layer could reach more than $97 \%$ at $2-14 \mu \mathrm{m}$. Thus, an Al layer was used as the bottom reflective metal layer of the resonant cavity absorber structure. According to the theory of optical interference absorption, It is easier to obtain a resonant cavity absorber structure with broad spectrum absorption with an intermediate dielectric layer with low refractive index [28]. The refractive index of air is 1, which is very suitable as the intermediate dielectric layer of the resonant cavity absorber structure. As seen in Figure 3, the $\mathrm{Si}_{3} \mathrm{~N}_{4}$, $\mathrm{SiO}_{2}$, and TiN have higher absorption at 3-14 $\mu \mathrm{m}, 8-10 \mu \mathrm{m}$, and 10-14 $\mu \mathrm{m}$, respectively, which is why we chose the $\mathrm{SiO}_{2} / \mathrm{TiN} / \mathrm{Si}_{3} \mathrm{~N}_{4}$ sandwich layers as the top absorption layer of the resonant cavity absorber structure. Moreover, the $\mathrm{Si}_{3} \mathrm{~N}_{4}$ and $\mathrm{SiO}_{2}$ layers are designed to be deposited on the upper and lower sides of TiN layer, respectively, where the $\mathrm{Si}_{3} \mathrm{~N}_{4}$ layer can act as a passivation layer and have a certain protective effect on the TiN layer, and the $\mathrm{SiO}_{2}$ layer can act as a supporting layer and play a positive role in supporting the overall structure. The $\mathrm{SiO}_{2} / \mathrm{TiN} / \mathrm{Si}_{3} \mathrm{~N}_{4}$ sandwich layers as the top absorption layer can well reduce the difficulty of preparation and the sensitivity of the resonant cavity absorber 
structure to the film thickness error and improve the mechanical strength, stability and yield of the resonant cavity absorber structure.

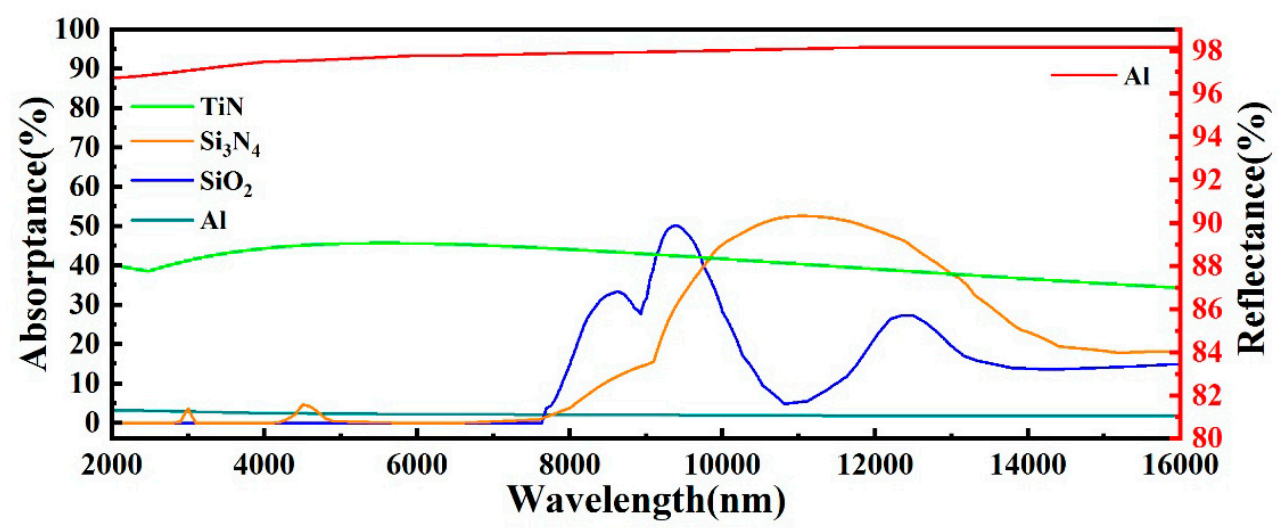

Figure 3. Calculated spectra of the $\mathrm{TiN}, \mathrm{Si}_{3} \mathrm{~N}_{4}, \mathrm{SiO}_{2}$, and $\mathrm{Al}$ layers.

Based on the theory of optical interference absorption, we used the Essential Macleod to simulate and calculate the optical thicknesses of the intermediate dielectric layer and top absorption metal layer, thereby adjusting the absorption wavelength range of the structure, as shown in Figure 4. The simulation and calculation results show that the resonant cavity absorber structure has great absorption at 3-5 $\mu \mathrm{m}$ and 8-14 $\mu \mathrm{m}$ when the thicknesses of the air cavity, TiN layer and $\mathrm{Si}_{3} \mathrm{~N}_{4}$ layer are 2700, 20, and $250 \mathrm{~nm}$, respectively, as shown in Figure 2b. As shown in the red spectral curve in Figure $4 \mathrm{a}$, the average absorptances of the designed resonant cavity absorber structure are $\sim 89.56 \%$ and $\sim 93.51 \%$ at $3-5 \mu \mathrm{m}$ and 8-14 $\mu \mathrm{m}$, respectively, which is comparable to those of porous materials [12-17]. However, as shown in the black spectral curve in Figure $4 \mathrm{a}$, the conventional standard cavity absorption structure designed with $\mathrm{Al}$ as the bottom reflective metal layer, $\mathrm{SiO}_{2}$ as the intermediate dielectric layer, and $\mathrm{Ti}$ as the top absorption layer only has an absorptance close to $91 \%$ in 3-5 $\mu \mathrm{m}$ [18]. Therefore, the thermopile chip with the designed resonant cavity absorber structure can not only be used as the detector elements of the non-contact infrared thermometer and thermal imager, but also as the NDIR gas detector element for detection of $\mathrm{CO}_{2}, \mathrm{CO}, \mathrm{NO}_{2}$, and $\mathrm{CH}_{4}$ gases. Generally, the absorption of the resonant cavity absorber structure is highly sensitive to the thickness error of each layer, and the thickness of each layer needs to be accurately controlled during the preparation process to achieve the ideal absorption effect. In fact, the deposition processes of MEMS and CMOS both have a certain thickness error, so the Essential Macleod software was used to simulate the absorption spectra of the designed resonant cavity absorber structure, under mean thickness error of $5 \%$. As shown in Figure $4 \mathrm{~b}$, the absorption spectra of the designed resonant cavity absorber structure have no obvious deviation in absorptance compared with that of the theoretical design (Figure $4 b$ ). Thus, under the mean thickness error (5\%) of the general MEMS and CMOS deposition processes, the designed resonant cavity absorber structure still has high absorption and stability. The structure design using air as the middle dielectric layer and $\mathrm{SiO}_{2} / \mathrm{TiN} / \mathrm{Si}_{3} \mathrm{~N}_{4}$ sandwich layers as the top absorption layer can effectively broaden the absorption wavelength range and reduce the sensitivity to thickness error. 
(a)
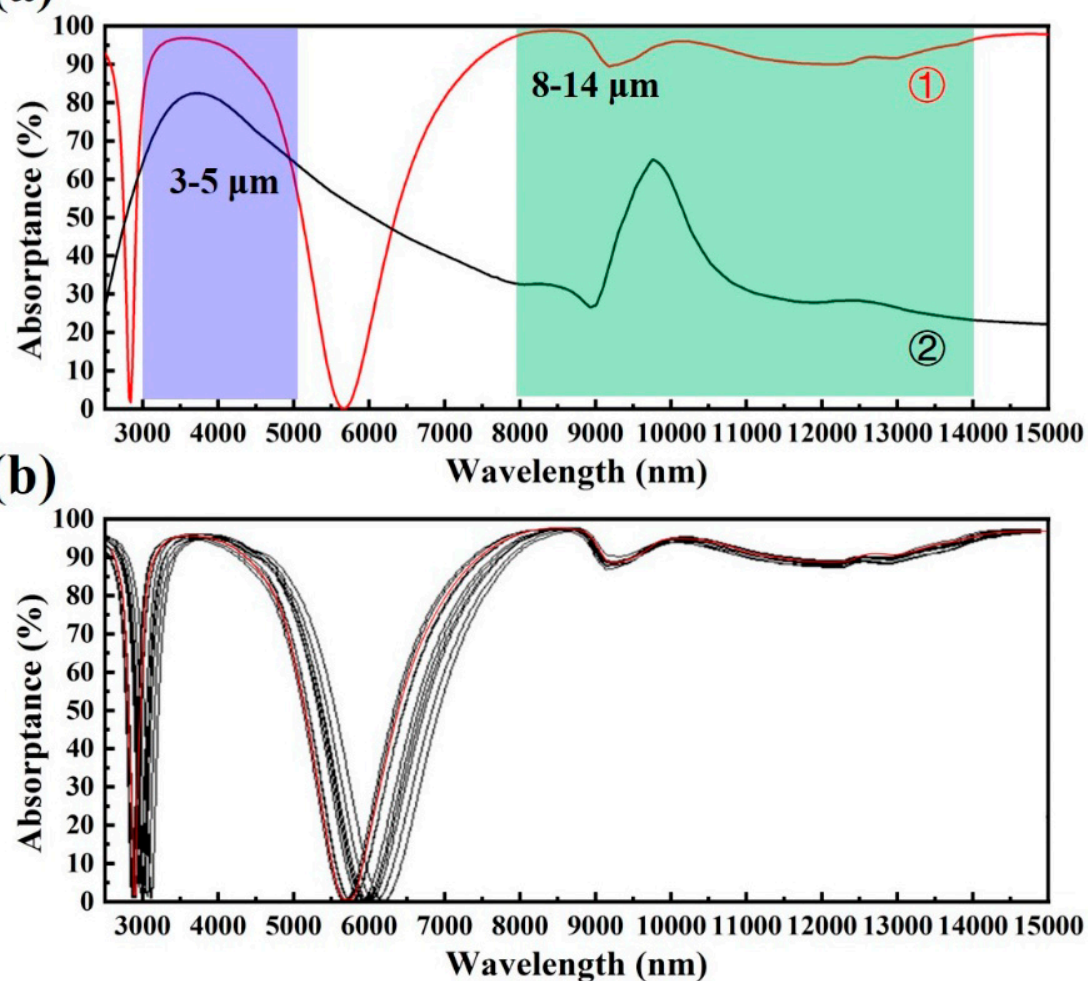

Figure 4. Theoretical absorption spectra of the designed resonant cavity absorber structures without (a) and (b) with mean thickness error of $5 \%$.

\section{Design of Thermopile Chip}

Based on the designed resonant cavity absorber structure, we propose a new type of thermopile chip structure, as shown in Figure 5. In this paper, we adopted monocrystalline silicon as the substrate and N-/P-Poly-Si as the thermocouple. The $\mathrm{SiO}_{2}$ layers were used as the support, insulating and passivation layers of the thermopile. The hot junctions of the thermopile were laid on the floating membrane, and the cold junctions were distributed on the center of substrate. Moreover, the N-Poly-Si and P-Poly-Si were connected using $\mathrm{Al}$ as interlayer at the hot junctions and the cold junctions of the thermopile, respectively.

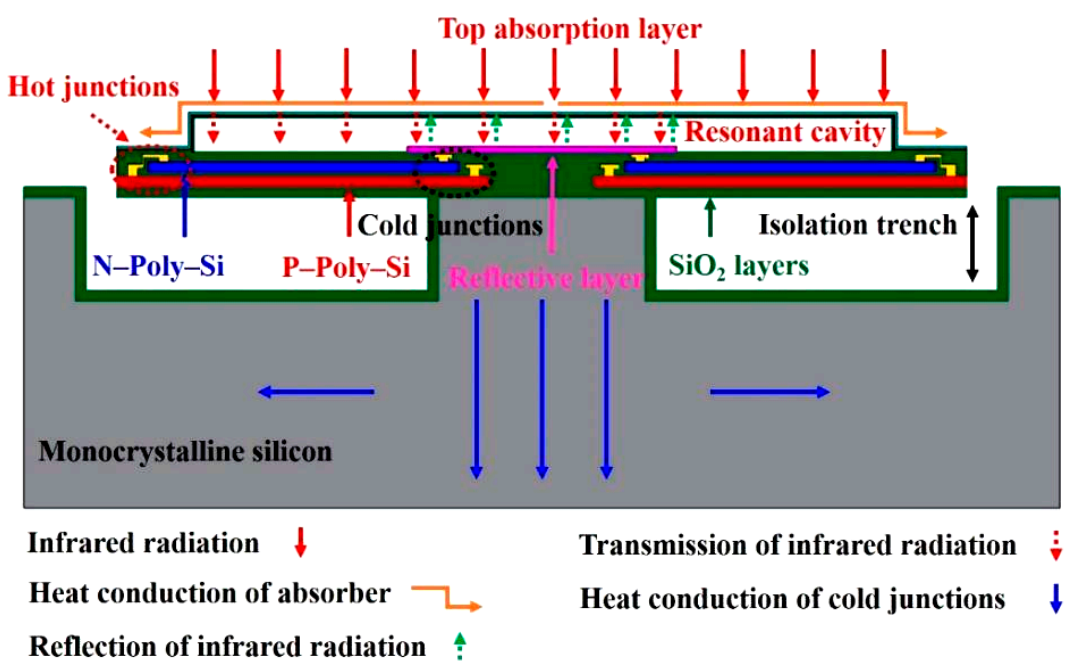

Figure 5. Schematics of structure and energy flow of thermopile chip with resonant cavity absorber structure. 
The responsivity $(R)$, noise equivalent power $(N E P)$, specific detectivity $\left(D^{*}\right)$, and time constant $(T)$ are the main three performance parameters for evaluating the thermopile chip, and $R$ is the most obvious and direct way to characterize the thermopile chip by the ratio of $\Delta U$ to incident infrared radiation power $\left(P_{0}\right)$ and can be calculated from Equation (1) [3]:

$$
R=\frac{\Delta U}{P_{0}}
$$

When infrared radiation is applied to the thermopile chip, there will be a temperature difference ( $T_{\text {diff }}$ ) between the hot junctions and the cold junctions of the thermopile, and $T_{\text {diff }}$ is converted into a measurable output voltage $(\Delta U)$ based on the Seebeck effect. The $\Delta U$ for a thermopile is then calculated from Equation (2) [3]:

$$
\Delta U=N T_{\text {diff }}\left|\alpha_{\mathrm{A}}-\alpha_{\mathrm{B}}\right|=N T_{\text {diff }} \alpha_{\mathrm{AB}}
$$

Therefore, increasing the $T_{\text {diff }}$ between the hot junctions and the cold junctions of the thermopile is the most direct and effective way to improve the performance of the thermopile chip.

In order to better understand and design the structure of the thermopile chip and make the designed resonant cavity absorber structure be perfectly combined with the thermopile chip, we used the finite element analysis software to simulate the thermopile chip's thermal field. As shown in Figure 6, compared with other double-layer suspension thermopile chips, the thermopile chip we designed has a higher $\mathrm{T}_{\text {diff }}$ between the hot junctions and the cold junctions [29-31]. Since both the doped polysilicon and $\mathrm{SiO}_{2}$ layers have certain absorption characteristic of infrared radiation, the cold junctions of the thermopile also have infrared absorption characteristic $[20,21]$. When the infrared radiation is irradiated on the surface of the thermopile chip, the cold junctions will also perform infrared absorption and light-to-heat conversion except the hot junctions and the infrared absorber. As shown in Figure 6a, the absorption of infrared radiation by the cold junctions will increase the temperature of the cold junction and thus weaken the responsivity of the thermopile chip. To solve this problem, we designed the cold junctions of the thermopile specifically, that is, the bottom reflective metal layer ( $\mathrm{Al})$ of the resonant cavity absorber structure was deposited on the cold junctions of the thermopile. Figure 3 shows that the Al layer has very low absorptance and very high reflectance $(\sim 97 \%)$ at $2-14 \mu \mathrm{m}$ so that the Al layer can well reflect the infrared radiation irradiated on the cold junctions, prevent the cold junctions from absorbing infrared radiation, and inhibit the rise of temperature, resulting in further improvement of responsivity and specific detectivity (as shown in Figure 6b). Furthermore, the $\mathrm{Al}$ layer can also serve as the reflective metal layer of the resonant cavity absorber structure, forming the interference of light and strengthening the infrared absorption characteristic of the top absorption metal layer. The top absorption layer of the resonant cavity absorber structure can be connected to the hot junctions through the support column, which facilitates the transfer of the heat of the top absorption layer to the hot junctions as shown in Figure 6b. This can further increase the temperature difference between the hot junctions and the cold junctions, and reduce the response time of the thermopile chip. In particular, the intermediate dielectric layer (air) is located between the absorption layer and the thermopile, and as a result, the heat loss is reduced, and furthermore, the mutual restriction of area between the absorption zone and the thermocouple zone is also solved, leading to a very high duty cycle. Thus, the sizes of the designed thermopile chip can be further reduced while maintaining responsivity and specific detectivity compared with the three types of traditional thermopile chips. 

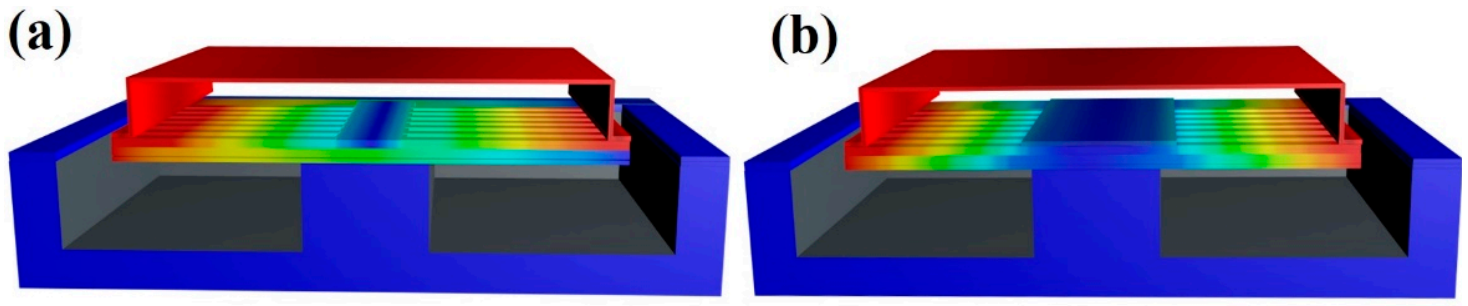

Figure 6. The (a) standard and (b) our design double suspension structures thermal field simulation.

\section{Preparation Process of Thermopile Chip}

On the basis of the designed structure of the thermopile chip, the preparation process was proposed, combining CMOS and MEMS processes. Firstly, an $\mathrm{SiO}_{2}$ layer of $\sim 200 \mathrm{~nm}$ thick was deposited on the surface of the silicon substrate as a masking layer using a thermal oxidation process, and then the photolithography and reactive ion etching (RIE) processes ware used to pattern and etch the $\mathrm{SiO}_{2}$ layer (Figure 7a). Secondly, the isolation trench with depth of $6000 \mathrm{~nm}$ was obtained by the RIE process for the bare silicon substrate (Figure $7 \mathrm{~b}$ ). Thirdly, a thermal oxidation process was used again to generate an $\mathrm{SiO}_{2}$ layer of $\sim 200 \mathrm{~nm}$ thick on the etched silicon substrate as a release barrier (Figure 7c). Then, a polysilicon layer of $\sim 3000 \mathrm{~nm}$ thick was grown by low pressure chemical vapor deposition (LPCVD) and then planarized, which served as a sacrificial release layer (Figure 7d). An $\mathrm{SiO}_{2}$ layer of $\sim 500 \mathrm{~nm}$ thick was deposited by LPCVD on the polysilicon layer, which served as a thermopile support layer (Figure 7e). A polysilicon layer of $\sim 500 \mathrm{~nm}$ thick was deposited by LPCVD on the support layer as one layer of the thermocouple and doped with boron (B) by ion implantation to form P-type polysilicon, and then the P-type polysilicon was patterned by the RIE process (Figure 7f). Next, an $\mathrm{SiO}_{2}$ layer of $\sim 100 \mathrm{~nm}$ thick was deposited again by LPCVD as the insulating layer of the P-type polysilicon layer (Figure 7g). A polysilicon layer of $\sim 500 \mathrm{~nm}$ thick was deposited by LPCVD on the insulating layer as another layer of the thermocouple and doped with phosphorus $(\mathrm{P})$ by ion implantation to form N-type polysilicon, and then the N-type polysilicon was patterned by the RIE process (Figure $7 \mathrm{~h}$ ). $\mathrm{An} \mathrm{SiO}_{2}$ layer of $\sim 100 \mathrm{~nm}$ thick was deposited by LPCVD as the insulating layer of the N-type polysilicon layer (Figure 7i). Subsequently, the two insulating layers were etched to form the connection holes at the hot junctions and the cold junctions by the RIE process (Figure 7j). Then, an Al layer of $\sim 500 \mathrm{~nm}$ thick was deposited by magnetron sputtering technology (MST) and patterned and etched by the photolithography and RIE processes, which served as the electrical connection between the thermocouples and the electrode (Figure 7k). The withstanding temperature of the substrate was greater than $700{ }^{\circ} \mathrm{C}$ while employing LPCVD to deposit the $\mathrm{SiO}_{2}$ or $\mathrm{Si}_{3} \mathrm{~N}_{4}$ layer, which brought about serious damage to the deposited $\mathrm{Al}$ layer. Finally, the $\mathrm{SiO}_{2}$ layer of $\sim 100 \mathrm{~nm}$ thick, as the passivation layer of the thermopile, was deposited by plasma enhanced chemical vapor deposition (PECVD) (Figure 7l).

For the preparation of the resonant cavity absorber structure, an Al layer of $\sim 100 \mathrm{~nm}$ thick was first deposited by MST as the bottom reflective metal layer, and then the photolithography and RIE processes were used to pattern and etch the Al layer (Figure 8a). The un-etched Al layer covered the cold junctions of the thermopile, which not only served as the reflective metal layer but also could reflect the infrared radiation irradiated at the cold junctions. Then, an amorphous silicon layer of $\sim 2700 \mathrm{~nm}$ thick was deposited by $\mathrm{PECVD}$ as the sacrificial layer (Figure $8 \mathrm{~b}$ ). Subsequently, an $\mathrm{SiO}_{2}$ layer of $\sim 100 \mathrm{~nm}$ thick was deposited by PECVD as the support layer of the top absorption metal layer; next, a TiN layer of $\sim 20 \mathrm{~nm}$ thick was deposited by MST as the top absorption metal layer, and then an $\mathrm{Si}_{3} \mathrm{~N}_{4}$ layer of $\sim 250 \mathrm{~nm}$ thick was deposited by PECVD as the passivation layer of the top absorption metal layer, thereby forming a complete $\mathrm{SiO}_{2} / \mathrm{TiN} / \mathrm{Si}_{3} \mathrm{~N}_{4}$ resonant cavity absorber structure (Figure 8c). Finally, the sacrificial layer composed of amorphous 
silicon was dry-etched and released by the release hole etching and $\mathrm{XeF}_{2}$ gas phase release processes to form the thermopile chip with the resonant cavity absorber structure (Figure 8d).

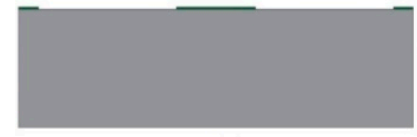

(a)

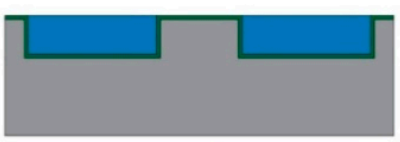

(d)

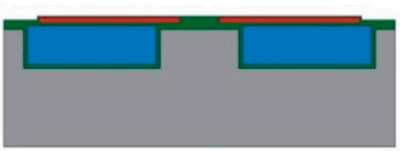

(g)

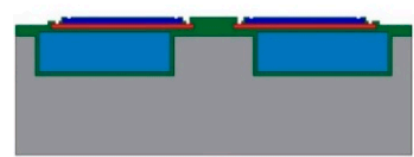

(j)

Silicon substrate

N-type polysilicon

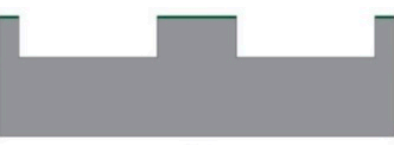

(b)

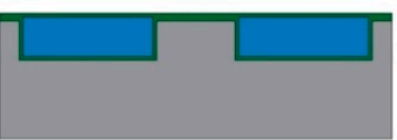

(e)

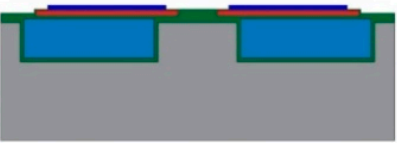

(h)

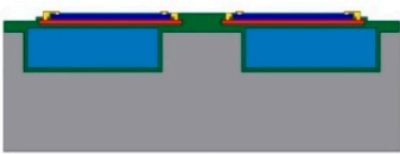

(k)

$\mathrm{SiO}_{2}$

Al

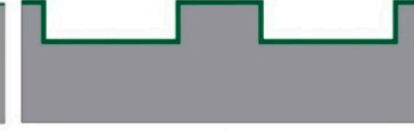

(c)

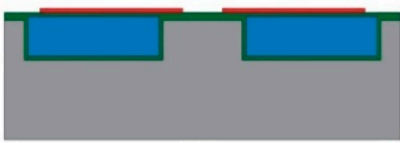

(f)

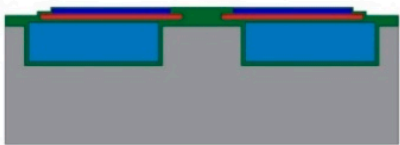

(i)

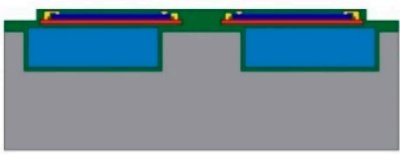

(I)

Polysilicon

P-type polysilicon

Figure 7. Schematic of preparation process of the designed thermopile. (a) deposition of $\mathrm{SiO}_{2}$ layer of $200 \mathrm{~nm}$ thickness, (b) isolation trench with depth of $6000 \mathrm{~nm}$, (c) thermal oxidation, (d) developing sacrificial release layer, (e) $500 \mathrm{~nm}$ thick thermopile support layer, (f) $500 \mathrm{~nm}$ thick polysilicon layer RIE process, (g) insulating layer, (h) polysilicon layer, (i) $100 \mathrm{~nm}$ insulating layer, (j) formation of connection holes, (k) $500 \mathrm{~nm}$ thick $\mathrm{Al}$ layer and (1) $100 \mathrm{~nm}$ thick $\mathrm{SiO}_{2}$ layer.

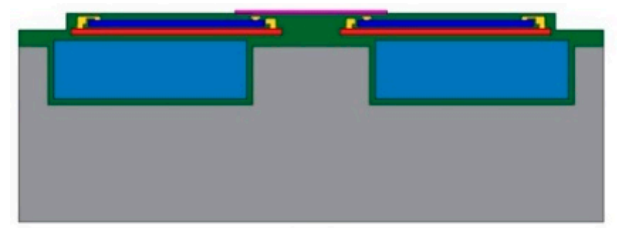

(a)

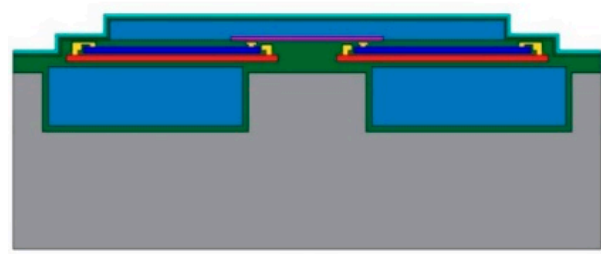

(c)

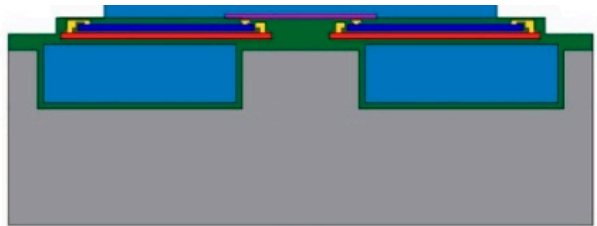

(b)

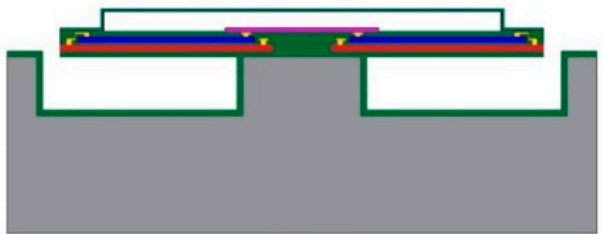

(d) Al Amorphous silicon

TiN

Figure 8. Schematic of preparation process of the designed resonant cavity absorber structure. (a) $100 \mathrm{~nm}$ thick bottom reflective metal layer, (b) $2700 \mathrm{~nm}$ thick amorphous silicon layer, (c) resonant cavity absorber structure, (d) final thermopile chip. 


\section{Conclusions}

A novel thermopile chip with resonant cavity absorber structure was designed by an optical simulation in this work. In the resonant cavity absorber structure, the $\mathrm{Al}$, air, and $\mathrm{SiO}_{2} / \mathrm{TiN} / \mathrm{Si}_{3} \mathrm{~N}_{4}$ sandwich layers were innovatively used as the bottom reflective metal layer, intermediate dielectric layer, and top absorption layer, respectively. The designed resonant cavity absorber structure exhibited $\sim 89.56 \%$ and $\sim 93.51 \%$ average absorptances at 3-5 $\mu \mathrm{m}$ and 8-14 $\mu \mathrm{m}$, respectively. In particular, the bottom reflective metal layer (Al) was deposited on the cold junctions of the thermopile, which made the Al layer not only act as the reflective metal layer to reflect the infrared radiation and to form the resonant cavity absorber structure, but also prevented the cold junctions from absorbing infrared radiation and inhibiting the rise of temperature. As a result, the temperature difference between the hot junctions and the cold junctions was increased, and the responsivity of the thermopile chip was improved. Moreover, the duty cycle of the thermopile chip was greatly improved due to the double-layer suspension structure. Compared with the traditional thermopile chips, the sizes of the designed thermopile chip can be further reduced while maintaining responsivity and specific detectivity.

Author Contributions: Conceptualization, H.H. and S.H.; methodology, J.Y., M.O., and G.L.; validation, J.L. and H.S.; formal analysis, S.H. and G.Q.; writing-original draft preparation, H.H. and J.Y.; writ-ing—review and editing, S.H. and M.T.N.; visualization, J.Y.; supervision, S.H. and M.T.N.; project administration, S.H., G.Q., A.A.G. and M.T.N.; funding acquisition, M.A. and M.M.A.-A. All authors have read and agreed to the published version of the manuscript.

Funding: This work was supported by the National Natural Science Foundation of China (51572111, 51950410596), the Key Research and Development Plan (BE2019094), The authors are grateful to the Deanship of Scientific Research, King Saud University for funding through Vice Deanship of Scientific Research Chairs and thankful to the financial support funded by the Deanship of Scientific Research at Princess Nourah bint Abdulrahman University through the Fast-track Research Funding Program; Research and Innovation Projects (KYCX19_1588), Six Talent Peaks Project (TD-XCL-004), 333 Talents project (BRA2017387) and Qing Lan Project ([2016]15) of Jiangsu Province.

Data Availability Statement: Data are available in the paper.

Conflicts of Interest: The authors declare no conflict of interest.

\section{References}

1. Graf, A.; Arndt, M.; Sauer, M.; Gerlach, G. Review of micromachined thermopiles for infrared detection. Meas. Sci. Technol. 2007, 18, R59-R75. [CrossRef]

2. Zhu, J.; Liu, X.; Shi, Q.; He, T.; Sun, Z.; Guo, X.; Liu, W.; Bin Sulaiman, O.; Dong, B.; Lee, C. Development Trends and Perspectives of Future Sensors and MEMS/NEMS. Micromachines 2019, 11, 7. [CrossRef]

3. Xu, D.; Wang, Y.; Xiong, B.; Li, T. MEMS-based thermoelectric infrared sensors: A review. Front. Mech. Eng. 2017, 12, 557-566. [CrossRef]

4. Stange, A.; Imboden, M.; Javor, J.; Barrett, L.; Bishop, D. Building a casimir metrology platform with a commercial MEMS sensor. Microsyst. Nanoeng. 2019, 5, 14. [CrossRef]

5. Chen, C.N. Temperature error analysis and parameter extraction of an 8-14 $\mu \mathrm{m}$ thermopile with a wavelength-independent absorber for tympanic thermometer. IEEE Sens. J. 2011, 11, 2310-2317.

6. Zhang, Z.; Zhang, H.; Liu, T. Study on body temperature detection of pig based on infrared technology: A review. Artif. Intell. Agric. 2019, 1, 14-26. [CrossRef]

7. Udina, S.; Carmona, M.; Carles, G.; Santander, J.; Fonseca, L.; Marco, S. A micromachined thermoelectric sensor for natural gas analysis: Thermal model and experimental results. Sens. Actuators B Chem. 2008, 134, 551-558. [CrossRef]

8. Vincent, T.; Gardner, J. A low cost MEMS based NDIR system for the monitoring of carbon dioxide in breath analysis at ppm levels. Sens. Actuators B Chem. 2016, 236, 954-964. [CrossRef]

9. Yin, Y.; Fang, Z.; Liu, Y.; Han, F. Temperature-insensitive structure design of micromachined resonant accelerome-ters. Sensors 2019, 19, 1544. [CrossRef] [PubMed]

10. Hirota, M.; Nakajima, Y.; Saito, M.; Uchiyama, M. $120 \times 90$ element thermoelectric infrared focal plane array with precisely patterned Au-black absorber. Sens. Actuators A Phys. 2007, 135, 146-151. [CrossRef]

11. Li, Y.L.; Zhou, H.; Li, T.; Wang, Y.; Liu, Y.X.; Wang, Y.L. CMOS-compatible $8 \times 2$ thermopile array. Sens. Actuators A Phys. 2010, 161, 120-126. [CrossRef] 
12. Mao, H.; Chen, Y.; Ou, Y.; Ou, W.; Xiong, J.; You, C.; Tan, Q.; Chen, D. Fabrication of nanopillar forests with high infrared absorptance based on rough poly-Si and spacer technology. J. Micromech. Microeng. 2013, 23, 95033. [CrossRef]

13. De Luca, A.; Cole, M.T.; Hopper, R.H.; Boual, S.; Warner, J.H.; Robertson, A.R.; Ali, S.Z.; Udrea, F.; Gardner, J.W.; Milne, W.I. Enhanced spectroscopic gas sensors using in-situ grown carbon nanotubes. Appl. Phys. Lett. 2015, 106, 194101. [CrossRef]

14. Xia, Y.; Xue, C.Y.; Ou, W.; Yuqn, F.; Zhao, L. A design of thermopile infrared detector based on black silicon as absorption. Instrum. Tech. Sens. 2012, 25, 581-584.

15. Chen, C.-N. Fully quantitative characterization of CMOS-MEMS polysilicon/titanium thermopile infrared sensors. Sens. Actuators B Chem. 2012, 161, 892-900. [CrossRef]

16. Zhao, L.; He, X.; Li, J.; Gao, X.; Jia, J. Electrosprayed carbon-based black coatings for pyroelectric detectors. Sens. Actuators A Phys. 2013, 196, 16-21. [CrossRef]

17. He, Y.; Wang, Y.; Li, T. Performance Enhanced Thermopile with Rough Dielectric Film Black. IEEE Electron Device Lett. 2020, 41, 593-596. [CrossRef]

18. Roncaglia, A.; Mancarella, F.; Cardinali, G. CMOS-compatible fabrication of thermopiles with high sensitivity in the 3-5 $\mu$ m atmospheric window. Sens. Actuators B Chem. 2007, 125, 214-223. [CrossRef]

19. Ashraf, S.; Mattsson, C.G.; Thungstrom, G.; Asharaf, S.; Asharf, S. Fabrication and Characterization of a SU-8 Epoxy MembraneBased Thermopile Detector with an Integrated Multilayered Absorber Structure for the Mid-IR Region. IEEE Sens. J. 2019, 19, 4000-4007. [CrossRef]

20. Jutzi, F.; Wicaksono, D.H.B.; Pandraud, G.; de Rooij, N.; French, P.J. Far-infrared sensor with LPCVD-deposited low-stress Si-rich nitride absorber membrane: Part 2. Thermal property, and sensitivity. Sens. Actuators A Phys. 2009, 152, 119-125. [CrossRef]

21. Xu, D.; Xiong, B.; Wang, Y. Design, fabrication and characterization of a front-etched micromachined thermopile for IR detection. J. Micromech. Microeng. 2010, 20, 115004. [CrossRef]

22. Wang, K.; Xue, C.; Liang, T.; Jiao, B.; Zhang, W.; Chen, D.; Xiong, J. Thermopile Infrared Detector with Detectivity Greater Than $108 \mathrm{cmHz}(1 / 2) / \mathrm{W}$. J. Infrared Millim. Terahertz Waves 2010, 31, 810-820. [CrossRef]

23. Lei, C.; Mao, H.; Yang, Y.; Ou, W.; Xue, C.; Yao, Z.; Ming, A.; Wang, W.; Wang, L.; Hu, J.; et al. A double-end-beam based infrared device fabricated using CMOS-MEMS process. Sens. Rev. 2016, 36, 240-248. [CrossRef]

24. Cao, L.M.; Zhang, Y.Z.; Sun, S.J.; Guo, H.; Zhang, Z. Structure design and test of MEMS thermocouple infrared detector. Microsyst. Technol. 2018, 24, 2463-2471.

25. Bao, A.; Lei, C.; Mao, H.; Li, R.; Guan, Y. Study on a High Performance MEMS Infrared Thermopile Detector. Micromachines 2019, 10, 877. [CrossRef] [PubMed]

26. Chang, K.-C.; Lee, Y.-C.; Sun, C.-M.; Fang, W. Novel absorber membrane and thermocouple designs for CMOS-MEMS thermoelectric infrared sensor. In Proceedings of the 2017 IEEE 30th International Conference on Micro Electro Mechanical Systems (MEMS), Las Vegas, NV, USA, 22-26 January 2017; IEEE: New York, NY, USA, 2017; pp. 1228-1231.

27. Shen, T.-W.; Chang, K.-C.; Sun, C.-M.; Fang, W. Performance enhance of CMOS-MEMS thermoelectric infrared sensor by using sensing material and structure design. J. Micromech. Microeng. 2018, 29, 025007. [CrossRef]

28. Hou, H.; Huang, Q.; Liu, G.; Qiao, G. Enhanced performances of CMOS-MEMS thermopile infrared detectors using novel thin film stacks. Infrared Phys. Technol. 2019, 102, 103058. [CrossRef]

29. Chou, B.C.S.; Mang, O. Thermopile Infrared Sensor, Thermopile Infrared Sensors Array, and Method of Manufacturing the Same. U.S. Patent 6335478 B1, 1 January 2002.

30. Xie, J.; Lee, C.; Feng, H. Design, Fabrication, and Characterization of CMOS MEMS-Based Thermoelectric Power Generators. J. Microelectromech Syst. 2010, 19, 317-324. [CrossRef]

31. Chen, Y.; Mao, H.; Tan, Q.; Xue, C.; Ou, W.; Chen, D.; Xiong, J. Design of thermopile-based infrared detectors with suspended absorber-thermopile Bi-layers. J. Sens. Technol. 2014, 27, 730-735. 